\title{
Bone marrow derived-mesenchymal stem cell improves diabetes-associated fatty liver via mitochondria transformation in mice
}

\author{
Youkun $\mathrm{Bi}^{1,3+}{ }^{+}$, Xuejun Guo ${ }^{2^{*}{ }^{+}}$, Mengqi Zhang ${ }^{1,3+}$, Keqi Zhu ${ }^{1,3}$, Chentao Shi ${ }^{2}$, Baoqi Fan ${ }^{1}$, Yanyun Wu', \\ Zhiguang Yang ${ }^{1}$ and Guangju $\mathrm{Ji}^{{ }^{*}}$ (D)
}

\begin{abstract}
Background: Non-alcoholic fatty liver disease (NAFLD) has become a global epidemic disease. Its incidence is associated with type 2 diabetes mellitus (T2DM). Presently, there is no approved pharmacological agents specially developed for NAFLD. One promising disease-modifying strategy is the transplantation of stem cells to promote metabolic regulation and repair of injury.

Method: In this study, a T2DM model was established through 28-week high-fat diet (HFD) feeding resulting in T2DM-associated NAFLD, followed by the injection of bone marrow mesenchymal stem cells (BMSCs). The morphology, function, and transfer of hepatocyte mitochondria were evaluated in both vivo and in vitro.

Results: BMSC implantation resulted in the considerable recovery of increasing weight, HFD-induced steatosis, liver function, and disordered glucose and lipid metabolism. The treatment with BMSC transplantation was accompanied by reduced fat accumulation. Moreover, mitochondrial transfer was observed in both vivo and vitro studies. And the mitochondria-recipient steatotic cells exhibited significantly enhanced OXPHOS activity, ATP production, and mitochondrial membrane potential, and reduced reactive oxygen species levels, which were not achieved by the blocking of mitochondrial transfer.
\end{abstract}

Conclusion: Mitochondrial transfer from BMSCs is a feasible process to combat NAFLD via rescuing dysfunction mitochondria, and has a promising therapeutic effect on metabolism-related diseases.

Keywords: BMSCs, Diabetes, NAFLD, Mitochondrial, Mitochondrial transfer, Metabolism

\section{Introduction}

The global prevalence of non-alcoholic fatty liver disease (NAFLD) has significantly increased in parallel with obesity [1]. NAFLD is characterized by diffuse fatty infiltration, accompanied by non-alcoholic steatohepatitis

\footnotetext{
*Correspondence: pygxj@163.com; gj28@ibp.ac.cn

†Youkun Bi, Xuejun Guo and Mengqi Zhang have contributed equally to this work

${ }^{1}$ Institute of Biophysics, Chinese Academy of Sciences, Beijing 100101, China

2 Puyang Oilfield General Hospital, Affiliated to Xinxiang Medical College, Puyang city 457000, Henan Province, China

Full list of author information is available at the end of the article
}

(NASH), and hepatic fibrosis [2]. The metabolic disorder of triglycerides and cholesterol results in the accumulation of massive lipid droplets in hepatocytes and subsequent hepatic steatosis, facilitating the follow-up of insulin resistance $[3,4]$. The mechanistic basis of NAFLD and NASH is still not completely understood, and apart from insulin resistance, lipids, mitochondrial dysfunction, innate immunity, intestinal flora, genetic determinants, nutritional factors, and dietary structure also regulates the pathogenesis of NAFLD [5]. Many studies have reported a strong association between NAFLD and type 2 diabetes mellitus (T2DM), as over $70 \%$ of T2DM original author(s) and the source, provide a link to the Creative Commons licence, and indicate if changes were made. The images or other third party material in this article are included in the article's Creative Commons licence, unless indicated otherwise in a credit line to the material. If material is not included in the article's Creative Commons licence and your intended use is not permitted by statutory regulation or exceeds the permitted use, you will need to obtain permission directly from the copyright holder. To view a copy of this licence, visit http://creativecommons.org/licenses/by/4.0/. The Creative Commons Public Domain Dedication waiver (http://creativeco mmons.org/publicdomain/zero/1.0/) applies to the data made available in this article, unless otherwise stated in a credit line to the data. 
patients have NAFLD $[6,7]$. The persistent imbalance of hepatic lipid uptake, de novo lipogenesis, and lipid clearance contributes to hepatic steatosis [8,9]. Concomitant apoptosis and inflammation trigger the activation of stellate cells, leading to hepatic fibrosis, cirrhosis, and even hepatic carcinoma (HCC) [10].

Mitochondria play important roles in multiple metabolic processes, in addition to ATP generation, which is the most prominent [11]. The integrity of mitochondrial morphology and function is responsible for mediating apoptosis, ROS signaling, calcium signaling, and steroid synthesis $[12,13]$. Both human and animal studies have described mitochondrial dysfunction in NAFLD and T2DM individuals in mitochondrial enzyme activity, abnormal mitochondrial morphology and number, and calcium activity [10, 14]. Mitochondrial quality control (MQC) is a complicated regulatory process that is crucial for maintaining cellular homeostasis [15]. MQC disorders are involved in the occurrence and development of NAFLD. Mitochondria dynamics are defined by fusion and fission, and are crucial for mitochondrial homeostasis, mitochondrial DNA (mtDNA) inheritance, and mitochondrial distribution. Sustained pathological stress, such as oxidative insult and lipotoxicity, overwhelms the MQC, greatly contributes to mitochondrial injury, which is detrimental to hepatocyte fate. Furthermore, MQC medication modulation has therapeutic benefits when combatting NAFLD, as described in many reports [16].

A promising strategy for the treatment of liver diseases is based on the application of stem cells or their secretions [17-19]. Among all stem cells, mesenchymal stem cells (MSCs) are characterized by their selfrenewal potential and differentiation ability, leading to a good application in disease treatment $[20,21]$. The therapeutic effect of MSCs mainly relies on paracrine signaling, differentiation, and inflammatory actions [22]. Studies have documented that MSCs can renew defective mitochondria via mitochondrial transfer between MSCs and diseased cells [23-25]. Transferred mitochondria cater for significant health benefits, as they correct the status of pathological cells by regulating MQC and maintaining macromolecular biosynthesis and cytoplasmic pools of $\operatorname{NAD}^{+}[25,26]$. Many studies have confirmed that mitochondrial transfer between MSCs and damaged tissue is a core event in tissue repair [27]. The positive effect of mitochondrial transfer was first clarified by rescuing aerobic respiration, for example, by increasing the oxygen consumption, membrane potential and intracellular ATP level [28]. MSC mitochondria transfer has been widely reported in the cardiovascular, respiratory, neurological, and renal systems [26, 29]. While not only is the therapeutic effect of BMSCs in NAFLD rarely reported, but mitochondria transfer between BMSCs and steatosis hepatocytes has not been clearly described. In the present study, we have firstly revealed that BMSCs can alleviate the steatosis in diabetes-associated NAFLD mice via mitochondria transformation.

\section{Materials and methods \\ Experimental animals}

All mouse-relevant procedures were performed according to the Guide for the Care and Use of Laboratory Animals published by the U.S. National Institutes of Health (NIH Publication No. 85-23, revised 1996)[30], and with the approval of the Institute of Biophysics Committee for Animal Care (Approval No. SYXK2019062). During acclimatization, 6-week-old male C57BL/6 strain mice purchased from Beijing Vital River Laboratory Animal Technology Co. Ltd were kept under standard housing conditions ( $12 \mathrm{~h}$ light/dark cycle, humidity $40-60 \%$, temperature $22{ }^{\circ} \mathrm{C}$ ) with ad libitum access to food and water. After adaptive feeding for one week, the animals were randomly divided into two groups fed with a growth and maintenance diet with $4 \%$ fat content (ND group) and a high-fat diet with $60 \%$ fat content (HFD group).

\section{Glucose and insulin tolerance test}

After fasting for $16 \mathrm{~h}$, tail tip blood of mice was subjected to blood glucose assay via Roche Glucose Meter and matching blood glucose test strip, followed by disinfecting the wound. Glucose tolerance test (GTT) was implemented to monitor the blood dynamic at $15,30,60$, and $120 \mathrm{~min}$, adopting the above blood glucose measurement, after glucose solution injection (Sigma, $1.5 \mathrm{~g} /$ $\mathrm{kg}$, i.p.), before which the animals were fasted for $16 \mathrm{~h}$; however, drinking was allowed. In the insulin tolerance test (ITT), tail venous blood from fasted mice for $4 \mathrm{~h}$ was monitored at 15, 30, 45, and $60 \mathrm{~min}$, after insulin administration (Novolin R, $1 \mathrm{U} / \mathrm{kg}$, i.p.). Before GTT and ITT, the glucose concentration of tail venous blood was measured as the initial reading.

\section{BMSC administration}

The isolation, culture, and identification of BMSCs were completed as described in the Supplementary material. The certified BMSCs from 5 to passage 10 were selected as seed cells for intravenous injection.

BMSCs were digested with $0.25 \%$ trypsin, washed thrice with phosphate-buffered saline (PBS), and resuspended in saline. The cells were counted, and diluted to $1 \times 10^{6}$ cells $/ \mathrm{mL}$ in saline. For BMSC administration, the designed number of cells $\left(1 \times 10^{7}\right.$ cells $/ \mathrm{kg}$ body weight $)$ suspended in $200 \mu \mathrm{L}$ saline was gently injected via the caudal vein at $1 \mathrm{~mL} / \mathrm{min}$. Selfsame administration was performed in the animals of the control group, except for an equal volume of saline. 


\section{Histological analysis}

Animals were sacrificed at a specific time after the administration of BMSCs or an equal volume of saline.

After opening the chest, the liver was removed immediately, perfused with PBS to wash out the blood, and immersed in $4 \%$ paraformaldehyde for $48 \mathrm{~h}$. The selected tissues were embedded in paraffin after dehydration in $75 \%$ ethanol for $12 \mathrm{~h}$ and then cut into $5 \mu \mathrm{m}$ sections. The sections were deparaffinized and stained with hematoxylin and eosin (H\&E) according to standard protocols. The Leica DFC300FX pathological image analysis system was used for image scanning and capture.

\section{Electron microscope imaging of isolated primary $\mathrm{mHCs}$}

The mHCs were isolated using the method described in the Supplementary Material. Thereafter, these cells were planted in a coverslip (Thermo, Massachusetts) for attachment. Well-attached cells were fixed in $2.5 \%$ glutaraldehyde at $4{ }^{\circ} \mathrm{C}$ overnight. The fixed $\mathrm{mHCs}$ were cut into ultrathin sections after performing a series of processingbased standard protocol [31]. A TEM (Thermo Fisher's Tecnai Spirit $120 \mathrm{kV}$ ) photographed the microscopic structure of the sections plated on the copper mesh.

\section{Establishment of steatotic cell model}

Free fatty acids (FFAs) are a good choice for establishing a steatotic cell model. Well-growing HepG2 cells at $80 \%$ confluence were treated with FFA medium (DMEM medium with $10 \% \mathrm{FBS}$ and $300 \mathrm{nM}$ oleic acid as well as $300 \mathrm{nM}$ sodium palmitate) for $36 \mathrm{~h}$ at $37^{\circ} \mathrm{C}$ in an incubator. Oil Red $\mathrm{O}$ staining and TEM micrograph of cell thin sections supported the identification of the above established NAFLD model in vitro.

\section{Construction of mito-GFP cell line}

The lentivirus infection method was used to establish cell lines stably expressing GFP in the mitochondria. Three plasmids, pLV-mitoGFP (Addgene, 44385), psPAX2 (Addgene, 12260), and pMD2.G (Addgene, 12259) were co-transfected into HEK293T cells at $80 \%$ confluency for $48 \mathrm{~h}$, and the supernatant was collected. The lentivirus particles were prepared by filtering the supernatant with a $0.45 \mu \mathrm{m}$ filter. The medium of well-cultured cells was replaced with serum-free DMEM (Gibco, New York) contained 10 multiplicity of infection (MOI) lentivirus and $10 \mu \mathrm{g} / \mathrm{mL}$ polybrene, and then cultured in an incubator at $37^{\circ} \mathrm{C}$ for $12 \mathrm{~h}$. The medium was replaced with a complete medium for $48 \mathrm{~h}$ of culture. Thereafter, these cells were digested with $0.25 \%$ trypsin to challenge the flow cytometry sorting to deliver signal cells with GFP expression to each well of a 96-well plate. A screening medium with $2.5 \mu \mathrm{g} / \mathrm{mL}$ puromycin was added to the above culture dish for cell expansion. After successive passages in the screening medium, cell line stably expressing GFP in the mitochondria was constructed. This study established HepG2 cells and BMSCs stably expressing GFP in mitochondria, named HepG2-mito-GFP, and BMSCs-mitoGFP, respectively.

\section{Detection of cellular ATP levels and oxygen consumption measurements}

When the cells reached $90 \%$ confluency, they were ready to be lysed ATP production analysis using an enhanced ATP Assay Kit (Beyotime, China). The RLU or CPM levels were detected using a luminometer to evaluate ATP levels. The protein concentration of lysed samples was measured using Bradford assay kit (Sigma) to calculate the average ATP yield per $\mu \mathrm{g}$ of cell protein.

The oxygen consumption rate (OCR) was determined according to the protocols described previously using a Seahorse XF-96 extracellular flux analyzer (Seahorse Bioscience, Billerica). Approximately, $4 \times 10^{4} \mathrm{mHCs}$ were plated in 24-well plates and treated with F12/DMEM containing $1 \mathrm{mM}$ bovine serum albumen (BSA)-conjugated oleate acid/palmitate acid (OA/PA) (Sigma) and incubated for $24 \mathrm{~h}$ before detection. Three independent repetitions were performed. The protein concentration in each well was quantified using the BSA assay according to the manufacturer's instructions (Thermo). The OCR was normalized to the total protein concentration in each well.

\footnotetext{
(See figure on next page.)

Fig. 1 BMSC transplantation rescues T2D-associated NAFLD. A Experimental design for establishing T2D model and assessing the BMSC treatment on T2D-associated NAFLD. Six-week C57BL/6 J mice were fed with HFD throughout the trial. Two BMSC injections were performed at 32nd and 34th week. Additionally, two vehicle injections (normal saline) were set as control. B The dynamic monitoring of mice after BMSC or vehicle administration (started at 34th week). $N=10$ animals per group. C Representative images of ND mice and T2D-associated NAFLD mice administered with vehicle or BMSCs. The images were photographed at 45th week. D GTT and E ITT analyses were carried out to evaluate the sensitivity of mice at 45th week to glucose and insulin. $N=6$ animals per group. $\mathbf{F}$ Serum biochemical assay of mice at 45th week. Sera of mice at 45th week were isolated to detect ALT, AST, TG, and TCHO levels. $N=6$ animals per group. G Representative images of gross liver and assays for $\mathrm{HE}$ and oil red O-stained liver sections. $\mathbf{H}$ Image J software was utilized to assay steatosis degree of liver. $\mathrm{N}=7$ animals per group. I Homogenized liver tissues were subjected to TG detection. $N=6$ animals per group. All statistical data are represented as means $\pm s .{ }^{*} P<0.05 ;{ }^{* *} P<0.01 ;{ }^{* * *} P<0.001$. All imaging was performed and analyzed in a blinded fashion
} 

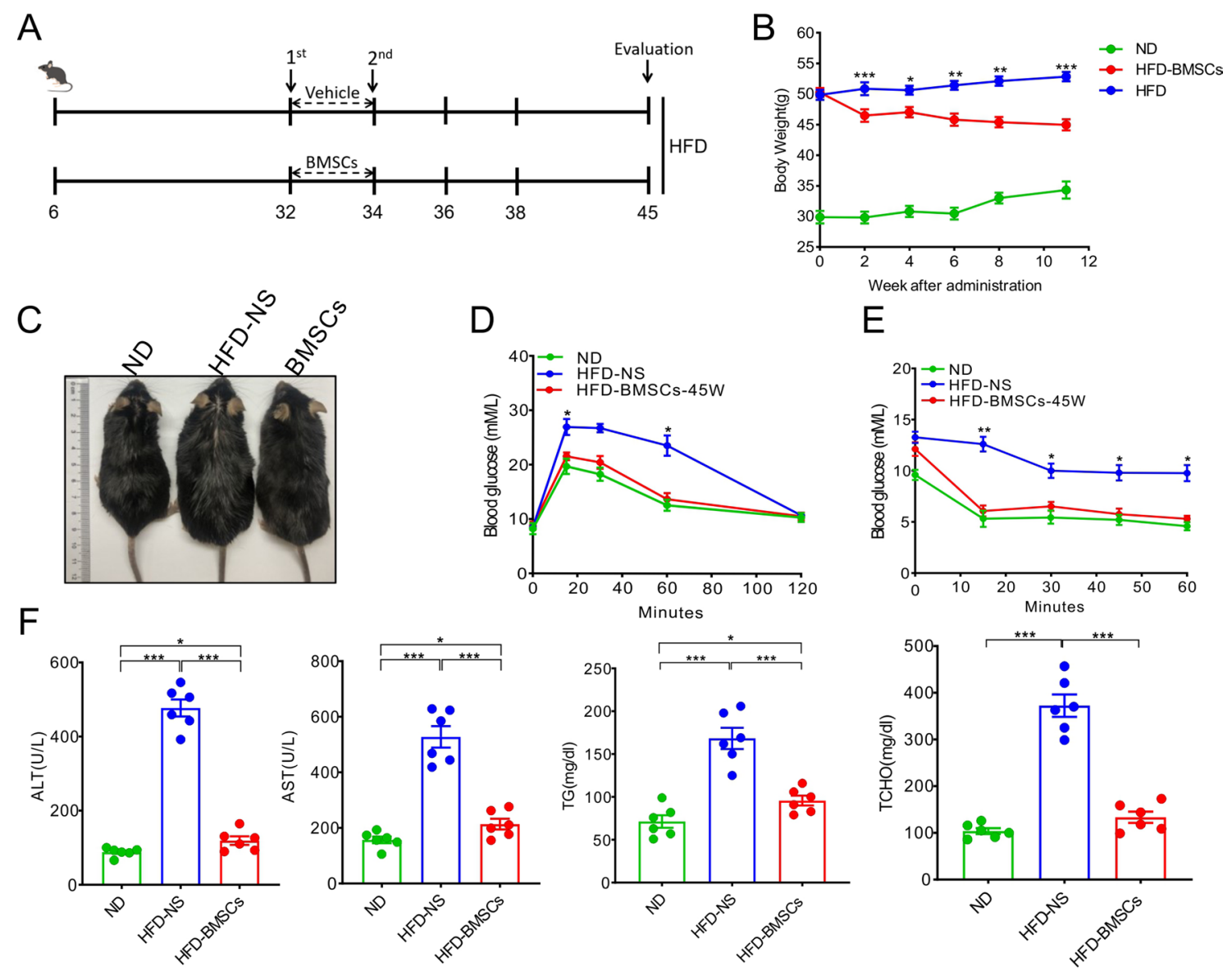

$\mathrm{E}$
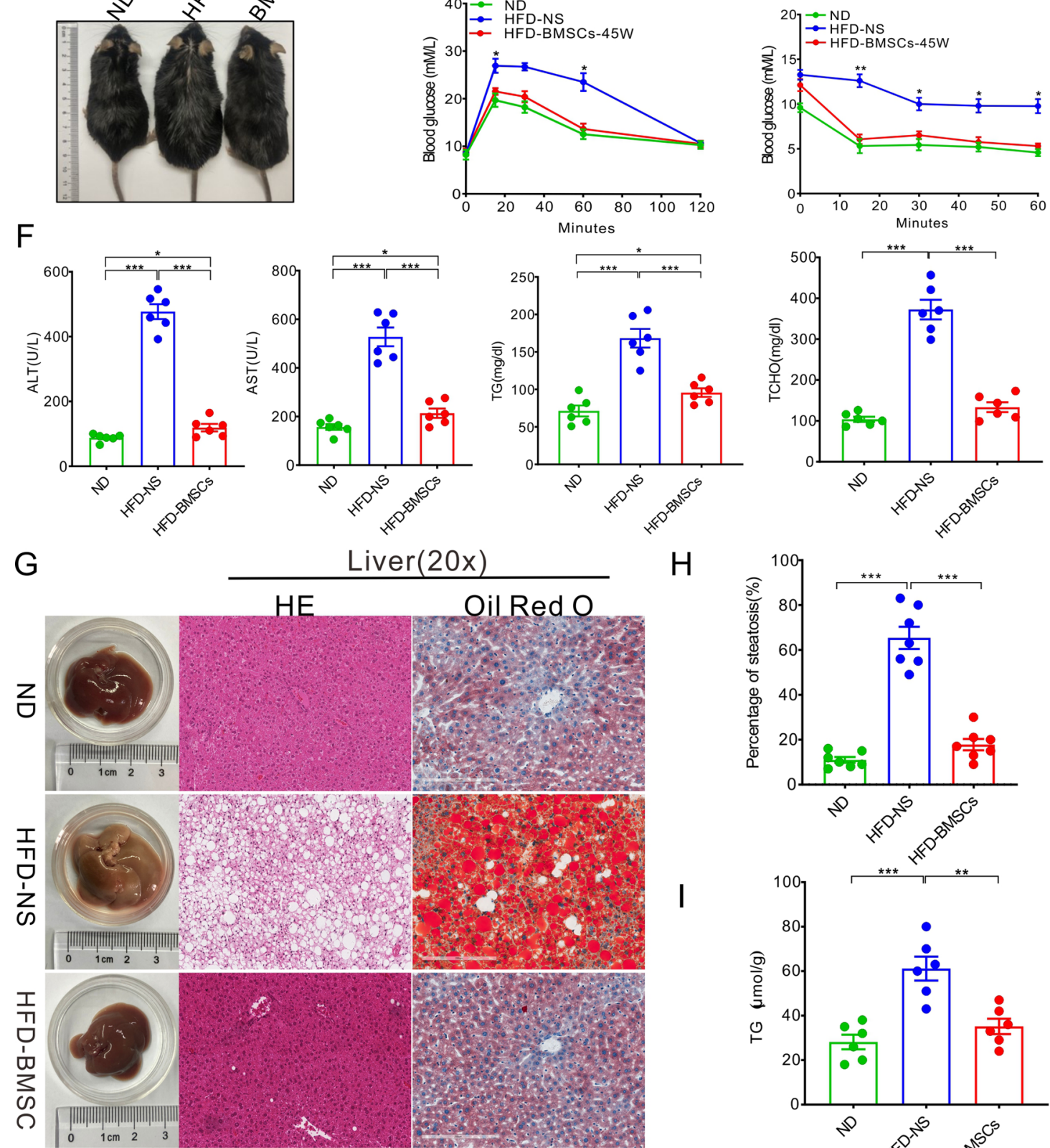

$\mathrm{H}$
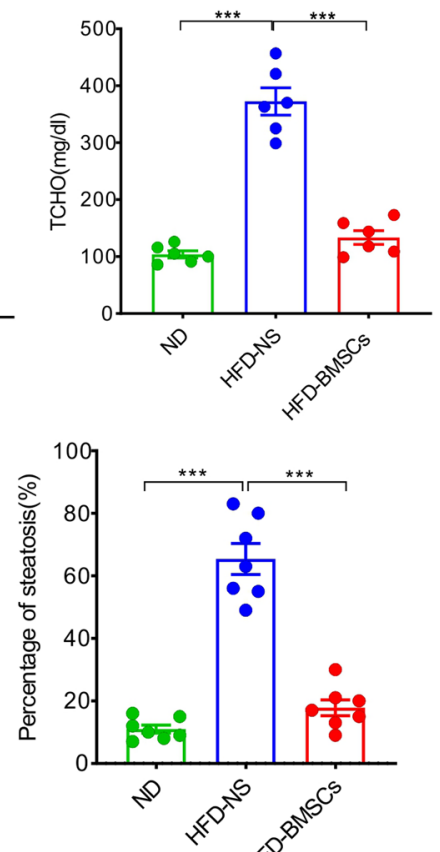

I

Fig. 1 (See legend on previous page.)

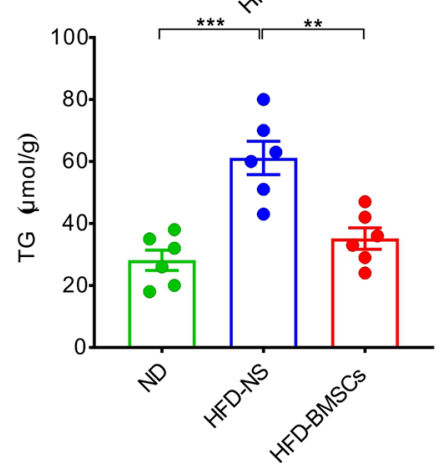




\section{Mitochondrial transfer detection in vivo and vitro}

The diabetic mouse model was anesthetized with a combination of ketamine and xylazine. A U-shaped incision was made, and the chest was opened to expose the liver. BMSCs-mito-GFP were mildly injected into T2D model mice $\left(1 \times 10^{7}\right.$ cells $/ \mathrm{kg}$ body weight in $200 \mu \mathrm{L}$ saline) through caudal vein. One week later, the livers of BMSC-transplanted mice were harvested and subjected to imaging via IVIS ${ }^{\circledR}$ lumina III In Vivo Imaging System (PerkinElmer, USA). Then the removed livers were fixed with $4 \%$ paraformaldehyde, embedded in paraffin, and sectioned at $10 \mu \mathrm{m}$ thickness. The sections were incubated with DAPI and photographed using a confocal microscope.

Thereafter, we isolated mHCs from T2DM mice and labeled them with 100 MitoTracker Red (Beyotime, C1049) at $37{ }^{\circ} \mathrm{C}$ for $30 \mathrm{~min}$ or not, and they were cocultured with BMSCs-mito-GFP for $12 \mathrm{~h}$. The live cell workstation was responsible for monitoring the mitochondrial movement. Also, BMSCs were isolated form 4-6-week-old male C57BL/6 strain mice and labeled with MitoTracker Red, and co-cultured with steatotic HepG2mito-GFP for $12 \mathrm{~h}$, followed by $2.5 \mu \mathrm{g} / \mathrm{mL}$ puromycin screen to kill BMSCs. The washed cells were fixed for confocal imaging.

Additionally, labeled mHCs isolated from HFD mice were co-cultured with BMSCs-mito-GFP with different cell proportions $(11: 1,1: 3,1: 5,1: 9$, and 1:11) for 24 or $48 \mathrm{~h}$, after which these cells were screened using $2.5 \mu \mathrm{g} /$ $\mathrm{mL}$ puromycin. These cells were washed and subjected to $0.25 \%$ trypsin digestion. Flow cytometry was used to screen double-stained cells.

To investigate the treatment effect of mitochondrial transfer on steatotic cells, we pasted a $0.22 \mu \mathrm{m}$ sterile membrane on the upper chamber of a transwell dish to block mitochondrial transfer, as described in Fig. 5D, and named this condition a mito-block. HepG2 cells were seeded at the bottom of the transwell dish with an FFA medium for $36 \mathrm{~h}$. Thereafter, the FFA medium was replaced with complete medium, after which BMSCs were inoculated in the upper chamber for $24 \mathrm{~h}$ or $48 \mathrm{~h}$ to perform other tests. HepG2 cells in the lower layer were washed out with PBS buffer three times, and cell RNA was extracted to prepare cDNA using a reverse transcription kit (Vazyme, R211-01). mtDNA was detected using PCR analysis, and the human-specific gene ACTB was used as the control. The mtDNA was detected using the primers listed in Additional file 1: Table S1.

\section{Statistical analysis}

The results were analyzed using a two-way ANOVA (multiple comparisons) or unpaired Student's $t$ test. Data are expressed as mean \pm SE. $P$ values considered statically significant were ${ }^{*} P<0.05$, ${ }^{* * *} P<0.01$, and ${ }^{* * * *} P<0.001$.

\section{Results}

The treatment of bone marrow mesenchymal stem cell (BMSC) administration on T2D-associated NAFLD mice T2D mice were selected from mice fed with HFD from 6th to 32nd week based on the diagnostic criteria for type 2 diabetic mice promulgated by the World Health Organization (WHO) [32] (Fig. 1A and Additional file 1: Fig. S1). Thereafter, they were randomized to either the vehicle or the treatment of identified and purified BMSCs (Additional file 1: Fig. S2) at 32nd week and 34th week. The monitoring of dynamic weight after treatment revealed that BMSC injection notably reduced the weight of HFD mice (Fig. 1B). The morphology photograph at 45th week highlighted the weight correction of BMSCs (Fig. 1C). However, BMSCs did not reverse the weight of HFD mice to normal levels. GTT and ITT analyses were performed at the 45th week, and the results together showed that HFD mice regained sensitivity to glucose and insulin (Fig. 1D, E). Thereafter, the sera from the 45-week-old mice were subjected to biochemical testing. BMSC treatment reversed the abnormally elevated ALT, AST, TG, and TCHO levels in HFD mice; however, these levels were still higher than the normal levels (Fig. 1F).

T2D is known to be closely related to obesity and NAFLD [6]. To investigate the effects of BMSC treatment on NAFLD, we performed a histopathological analysis of the liver at the 45th week (11 weeks after BMSC administration). We observed severe steatosis and significantly increased TG levels in the liver of HFD mice (Fig. 1G-I). BMSC administration completely reversed the steatosis in the liver of HFD mice, and this phenomenon was observed in all examined mice (total $n=10$ ). Additionally,

(See figure on next page.)

Fig. 2 BMSC transplantation rescues mitochondrial dysfunction. A TEM micrographs of isolated mHCs from ND mice and T2D-associated NAFLD mice administered with vehicle or BMSCs at 45th week. B The average number of mitochondria in each cell. The statistics are from random 25 cell fields per mice and 6 mice per group. C OCR analysis of isolated mHCs from ND mice and T2D-associated NAFLD mice administered with vehicle or BMSCs at 45th week. The mHCs come from 6 mice per group. D The ATP detection of isolated mHCs. The mHCs were isolated from 6 mice per group. E Real-time PCR describes the mtDNA/nDNA ration according to the previous report [60]. Relative quantification was performed on 6 animals per group. F The mRNA expression level of mitochondria-related genes in terms of dynamics and biogenesis. The RNA was extracted from homogenized liver tissues of 6 mice per group. G MDA detection of homogenized liver tissues of 6 mice per group. H, I MMP and ROS detection of $\mathrm{mHCs}$ from 6 mice per group. All statistical data are represented as means $\pm \mathrm{s} .{ }^{*} P<0.05 ;{ }^{* *} P<0.01 ;{ }^{* * *} P<0.001$ 
A

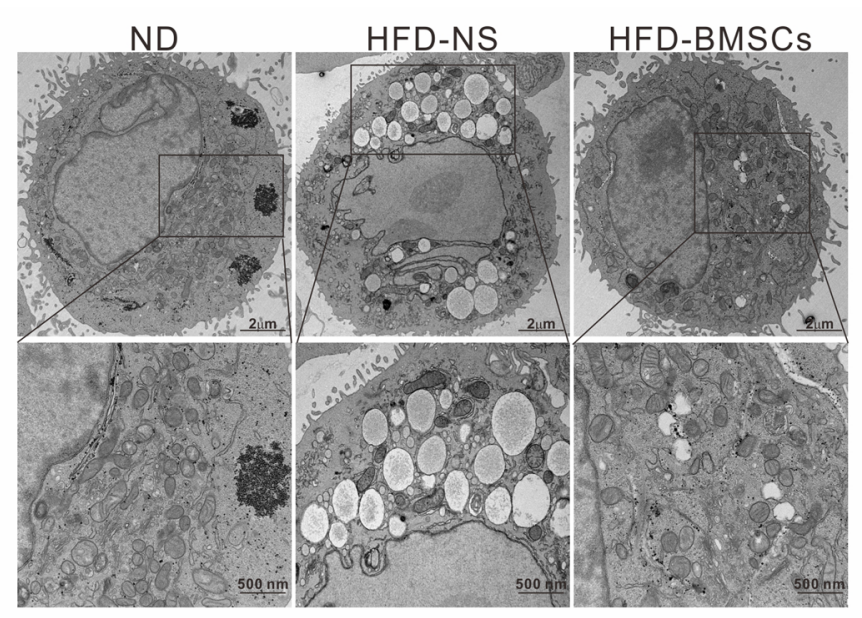

$\mathrm{C}_{20}$

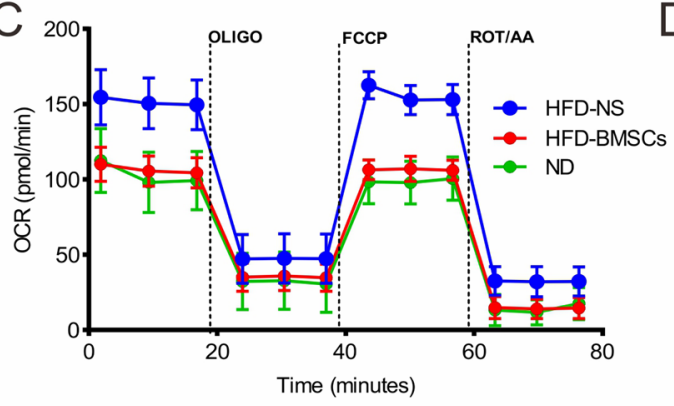

$\mathrm{F}$
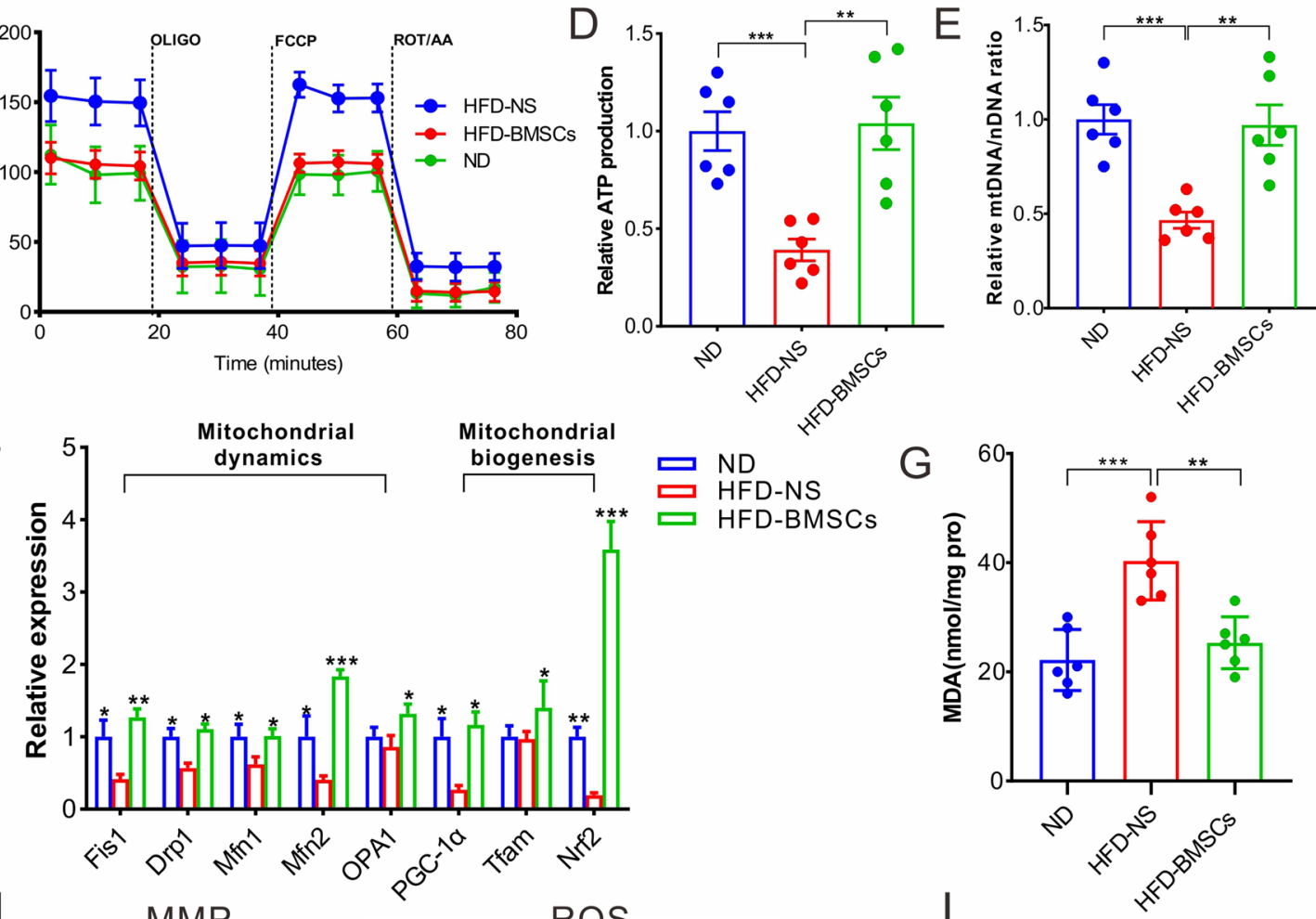

$\mathrm{H}$
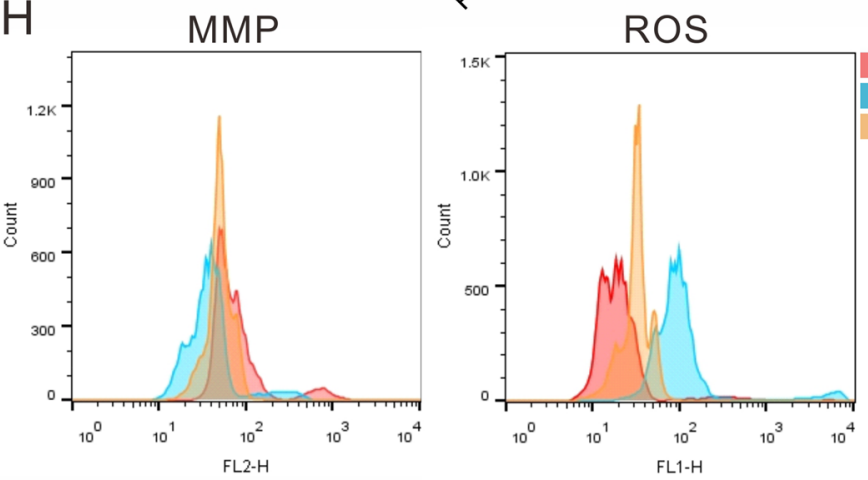

B

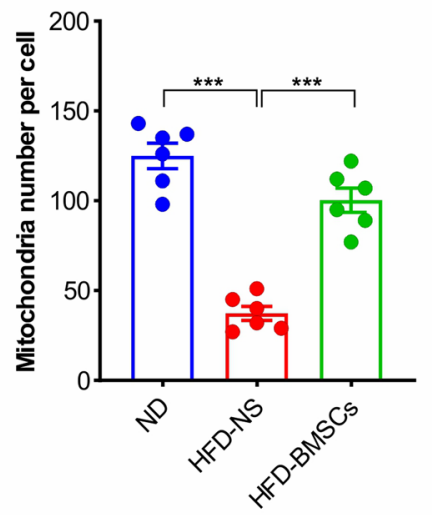

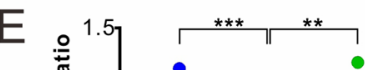

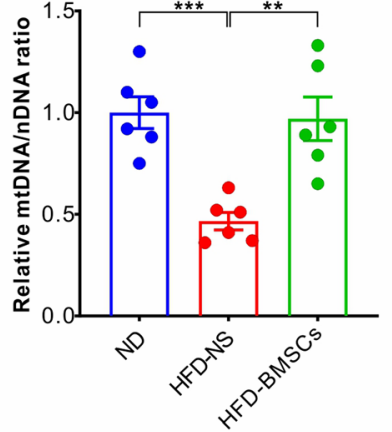

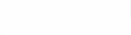

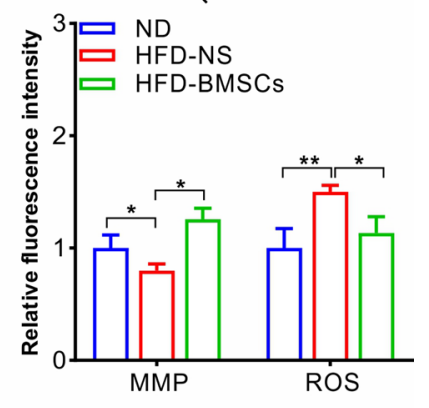

Fig. 2 (See legend on previous page.) 
brown adipose tissue (BAT) is physiologically crucial for energy metabolism. Pathological analysis revealed that HFD was an important driving factor for converting BAT into white adipose tissue (WAT). BMSCs also alleviated the above condition in the BAT of T2D mice; however, BAT did not return to normal levels in mice of the ND group (Additional file 1: Fig. S3).

\section{BMSCs improve the dysfunction of mitochondria in mHCs}

Mitochondria play a crucial role in physical metabolism $[25,26]$. It is also well known that a long-term HFD is responsible for mitochondrial dysfunction [33]. To investigate the effect of BMSCs on mitochondria in NAFLD mHCs, ultrathin sections of isolated mHCs were subjected to electron microscopy imaging for mitochondrial morphology observation. Micrographs revealed that HFD promoted the accumulation of lipid droplets in mHCs. The mitochondrial number significantly decreased, accompanied by morphological abnormalities such as concentration, the disappearance of cristae, and swelling (Fig. 2A, B). OCR value assessment of isolated $\mathrm{mHCs}$ clarified the elevation in oxygen consumption in HFD mice (Fig. 2C) in terms of base, maximal, and spare respiratory levels (Additional file 1: Fig. S4). The decrease in unit ATP production (Fig. 2D) and mtDNA copy number (Fig. 2E) further supported mitochondrial dysfunction in mHCs of HFD mice. BMSC treatment restored mitochondrial abnormalities to normal levels in multiple terms, such as morphology, mtDNA copy number, OCR, and unit ATP production (Fig. 2).

MQC is recognized by changing the structure and shape of mitochondria through fusion and fission processes in response to changes in the energy demand and supply [15]. Pathological stress disrupts mitochondrial biogenesis and dynamics, accompanied by corresponding changes in the expression of crucial genes, especially Fis1, Drp1, Mfn1, Mfn2, OPA1, PGC-1 $\alpha$, Tfam, and Nrf2 [34]. Liver tissues were homogenized for RNA extraction and cDNA preparation. Real-time polymerase chain reaction (PCR) was used to assess the changes in the expression of MQC-relevant genes using the primers listed in Additional file 1: Table S2. The results indicated that expression of nearly all test genes significantly decreased in the T2D model, and BMSC treatment corrected their expression to normal levels, and even to the levels lower than the normal levels (Fig. 2F).

Additionally, other indicators were used to evaluate mitochondrial activity. The malondialdehyde (MDA) level is an important parameter that reflects antioxidant potential. High MDA levels attenuate the activities of the respiratory chain complex and key enzymes in mitochondria, and continuous elevation of MDA level destroys the integrity of the mitochondrial membrane. Metabolic disorders result in a sharp rise in ROS levels. Excess ROS level increases the permeability of the mitochondrial double-layer membrane, which is responsible for follow-up adverse events, such as mitochondrial membrane potential (MMP) decrease, mitochondrial dysfunction, and apoptosis [35, 36]. This study found a significant increase in MDA and ROS levels in HFD mice compared to those in ND mice. MMP decline was also confirmed in the T2D model owing to the long-term HFD treatment. Conversely, BMSC treatment restored abnormal MDA, ROS, and MMP levels back to normal levels (Fig. 2G-I).

\section{BMSC treatment directly enhance the mitochondrial activity in vitro}

The 10th passage cells in good condition were planted in a confocal dish and incubated with $100 \mathrm{nM}$ Mito-Tracker Red (Beyotime) for $20 \mathrm{~min}$ at $37^{\circ} \mathrm{C}$. Confocal imaging revealed that green fluorescence in HepG2-mito-GFP had a perfect overlap with MitoTracker Red (Fig. 3A), which indicated the stable expression of GFP in mitochondria. HepG2-mito-GFP cells were plated at an appropriate density in a 6-well plate and cultured with free fatty acid (FFA) medium for $36 \mathrm{~h}$ at $37^{\circ} \mathrm{C}$ to induce steatosis (Fig. 3B). Oil Red O staining and transmission electron microscope (TEM) micrograph of thin cell sections together indicated that there was a large accumulation of lipid droplets in steatotic cells (Fig. 3C). TEM micrographs also showed that FFA additives contributed to mitochondrial abnormalities, such as swelling and a sharp decline in the mitochondrial number (Fig. 3D).

To investigate the effect of BMSCs on steatotic cells, HepG2-mito-GFP cells were cultured in FFA medium for

\footnotetext{
(See figure on next page.)

Fig. 3 BMSC intervention directly enhances the mitochondrial activity in vitro. A The establishment of HepG2-mito-GFP cell lines. The mitochondria were stained with MitoTracker Red. Scare bar represents $25 \mu \mathrm{m}$. B Trial design for establishing steatotic cell model and assessing the BMSC intervention effect: well-growing HepG2-mito-GFP cells were fed with FFA medium for 36 h, and then BMSCs were added for 48 h co-cultivation, followed by puromycin screening. Cells fed with complete medium were set as control. $\mathbf{C}$ Oil Red O stain detection of treated cells in $\mathbf{B}$ and the quantification of Oil Red O staining area. Three independent replicates were performed. D Representative TEM imaging of treated cells in B and the quantification of average mitochondrial number in the field at $500 \mathrm{~nm}$. Big droplets are labeled with asterisk. Twenty-five fields per group were taken into consideration. E Total ROS level was detected via FCM and quantitative analysis at $24 \mathrm{~h}$ and $48 \mathrm{~h}$. Three independent replicates were performed. F WB assay of target protein level. The relative expression level was determined by densitometry and normalized to $\beta$-actin levels. All statistical data are represented as means $\pm \mathrm{s}$. ${ }^{*} P<0.05$; ${ }^{* *} P<0.01{ }^{* * *} P<0.001$
} 


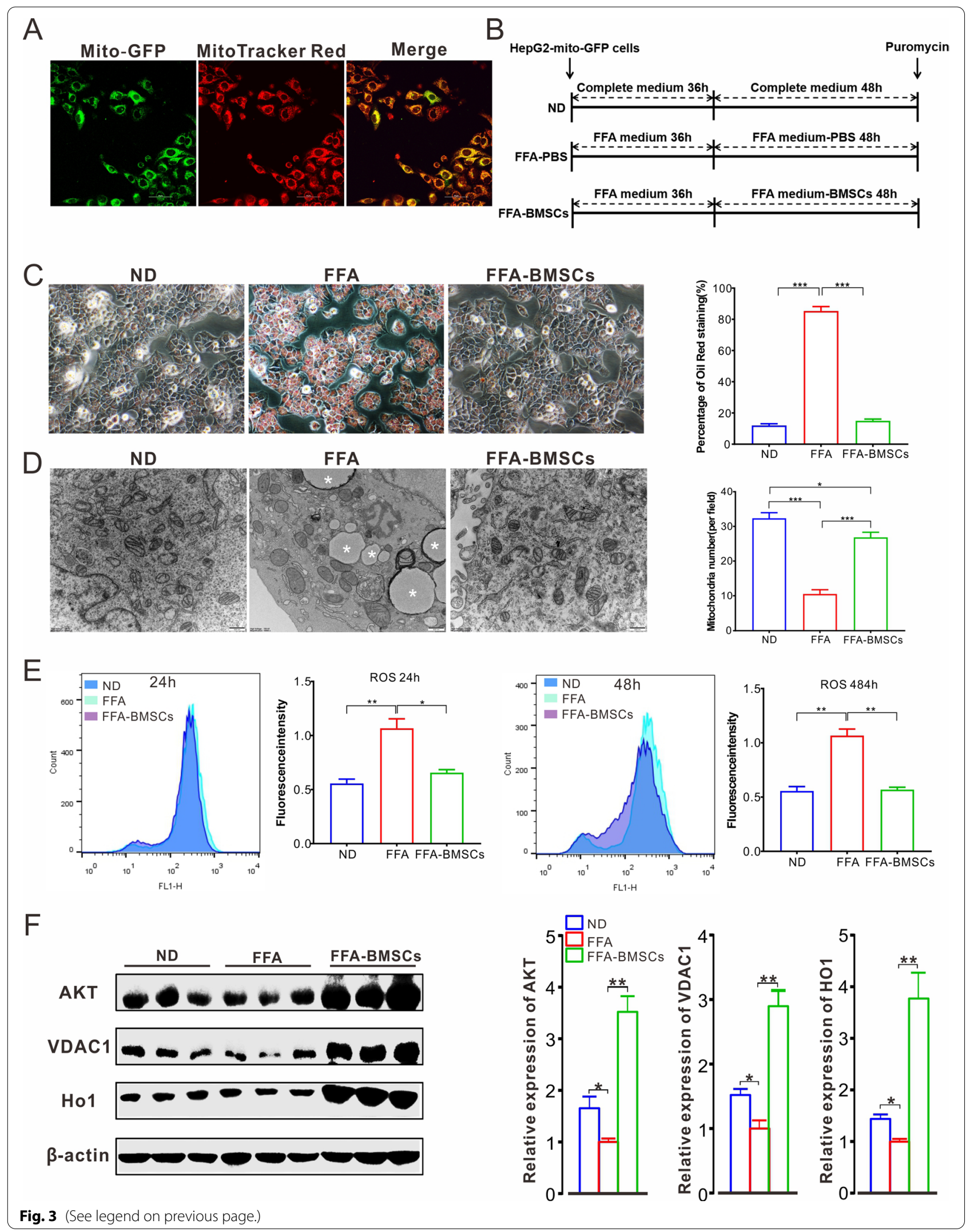


A

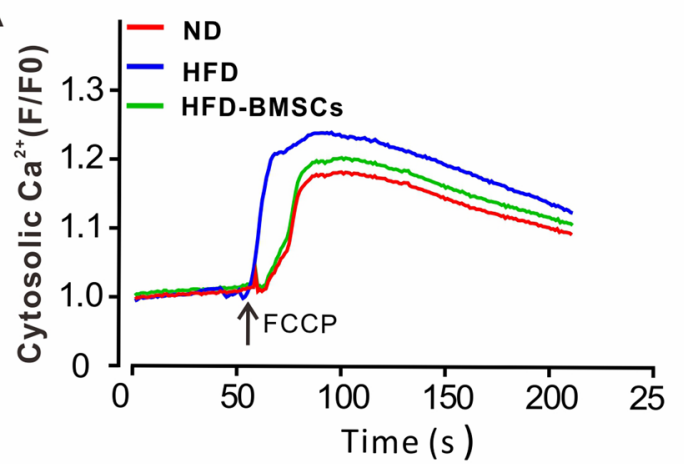

$\mathrm{B}$

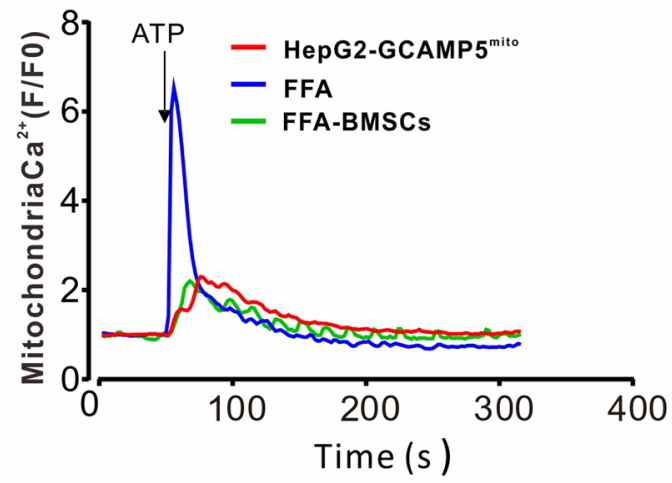

C

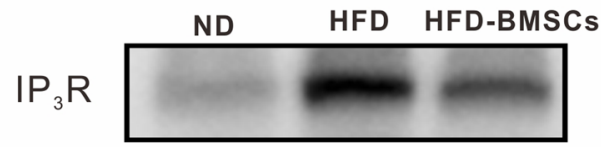

$\beta$-actin
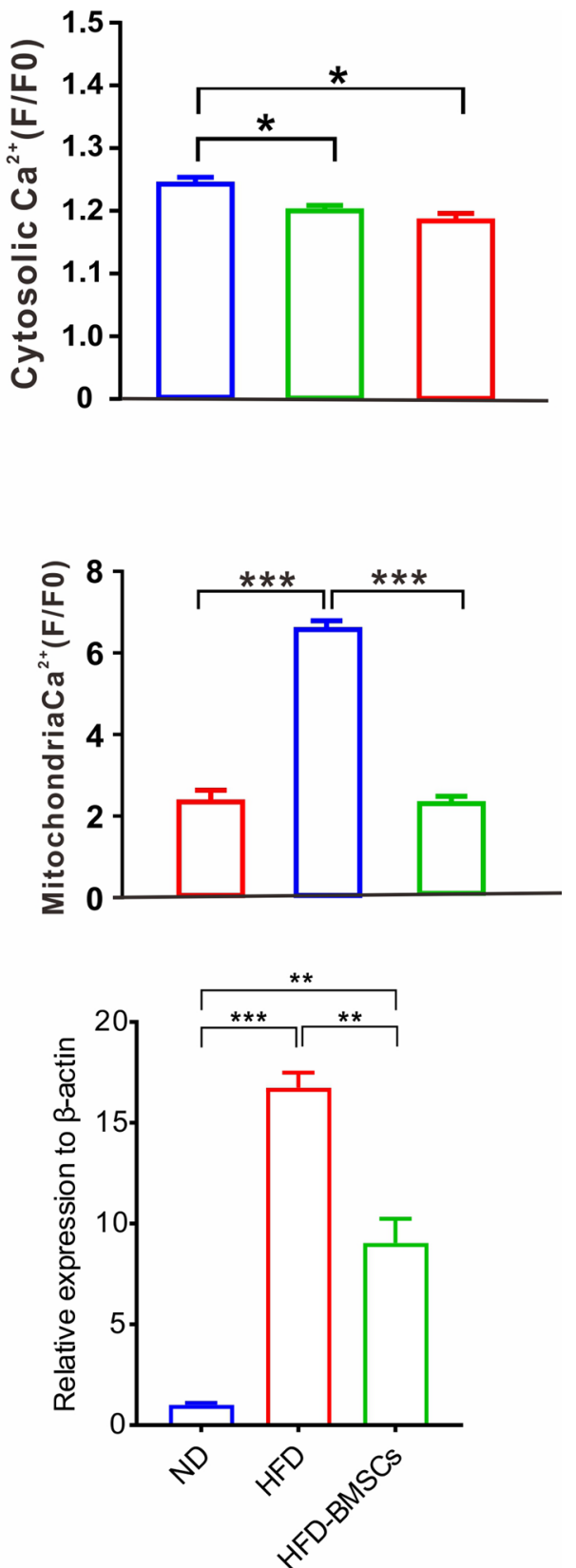

Fig. 4 BMSCs rescue the abnormal calcium activity of steatotic cells. A Representative $\mathrm{Ca}^{2+}$ transients induced by FCCP form linescan images recorded from isolated mHCs of ND (red), HFD (blue), and HFD-BMSCs (green) mice. B Representative $\mathrm{Ca}^{2+}$ transients induced by ATP form linescan images recorded from HepG2-GCAMPmito cells treated with complete medium (red), FFA medium (blue), and FFA medium combined with BMSCs (green). C The detection of IP3R expression in the liver of ND, HFD, and HFD-BMSCs mice. The relative expression was determined by densitometry and normalized to $\beta$-actin levels. All trials above were performed with three independent replicates, and the statistical data are represented as means \pm s. ${ }^{*} P<0.05 ;{ }^{* *} P<0.01 ; * * * 00.001$

$36 \mathrm{~h}$ and then co-cultured with BMSCs for another $24 \mathrm{~h}$ or $48 \mathrm{~h}$, followed by puromycin screening to kill viable BMSCs. The surviving cells were subjected to Oil Red $\mathrm{O}$ staining and TEM imaging. Both intuitively displayed
BMSC treatment-corrected steatosis in terms of a significantly decreased number of lipid droplets and mitochondrial recovery (Fig. 3B, C). Additionally, these cells were subjected to ROS detection using flow cytometry. 
The results revealed that BMSCs positively regulated the inhibition of total cell ROS production induced by lipotoxicity at $24 \mathrm{~h}$ and $48 \mathrm{~h}$ (Fig. 3E). Similarly, the elevated mitochondrial ROS level in steatotic cells was also significantly attenuated after BMSC intervention at $48 \mathrm{~h}$; however, it did not show a remarkable reduction at $24 \mathrm{~h}$ (Additional file 1: Fig. S5).

Previous studies have reported that some genes play a crucial role in regulating mitochondrial function. Among them, AKT participates in the determination of cell fate by restraining apoptosis induced by preventing cytochrome $\mathrm{C}$ release from the mitochondria [37]. VDAC1, a voltage-dependent anion channel, is closely related to the communication of mitochondria and cytoplasm [38]. HO-1 signaling protects cells from oxidative stress and inflammatory responses. Therefore, we performed western blot analysis targeting cell lysates in each group [39]. The results revealed that FFA feed significantly contributed to lowering the gene expression of AKT, VDAC1, and HO1 compared to that of ND. BMSC treatment further elevated the expression relative to the ND level (Fig. 3F).

\section{BMSCs rescue the abnormal calcium activity of steatotic cells}

The liver is a major metabolic organ that controls gluconeogenesis, glycogen storage, lipogenesis, and cholesterol and bile acid metabolism $[1,2]$. Alteration of $\mathrm{Ca}^{2+}$ at the cellular and organelle levels of the liver directly affects hepatic glucose production and lipogenesis [40, 41]. To investigate the effect of BMSCs on the calcium activity of steatotic cells, we measured the relative calcium concentration in the cytoplasm and mitochondria. First, we isolated primary hepatocytes from HFD mice, which were loaded with calcium probe fluo- 2 for $10 \mathrm{~min}$ at room temperature, and confocal fluorescence intensity dynamic curves were recorded. The results indicated that the cytoplasmic calcium activity of steatotic cells showed higher sensitivity to carbonyl cyanide $p$-trifluoromethoxyphenylhydrazone (FCCP) stimulation, an oxidative phosphorylation uncoupler, than that of normal mHCs. BMSC treatment reduced the calcium load in the cytoplasm of steatotic cells to normal levels (Fig. 4A). Thereafter, we established that HepG2 cells stably expressed
GCAMP5 in mitochondria, named HepG2-GCAMP5 mito. These cells were treated with FFA medium for $36 \mathrm{~h}$ for the next mitochondrial calcium detection. The calcium signal curve showed a steep rise after the steatotic cells were stimulated with ATP. This phenomenon was corrected to normal levels after co-culture with BMSCs (Fig. 4B).

IP3R directly regulates calcium signal transduction and mediates triglyceride storage in hepatocytes [42]. The activation of the IP3R signaling pathway is responsible for the elevated calcium concentration and steatosis in hepatocytes [43]. This study detected the expression of IP3R1 in the liver of each group of mice. The results indicated that BMSCs significantly reduced IP3R1 expression in HFD mice (Fig. 4C).

\section{Mitochondrial transfer from BMSCs to steatosis cells in vitro and in vivo}

These results indicated that BMSC treatment suppressed steatosis by correcting mitochondrial disorders. This study hypothesized that the mitochondria of BMSCs directly transfer into adjacent cells to combat pathological stress. Live imaging observed GFP signaling in liver after BMSCs-mito-GFP injection for one week (Fig. 5A). Confocal microscope imaging of paraffin sections also revealed green fluorescence accumulation around the hepatocyte nucleus (Fig. 5B), which initially verified the transfer of mitochondria from BMSCs to hepatocytes. Next, the isolated mHCs from T2DM mice were labeled with MitoTracker-Red and then co-cultured with BMSCs-mito-GFP. Dynamic monitoring in $12 \mathrm{~h}$ intuitively described the mitochondrial transfer from BMSCs-mito-GFP to adjacent hepatocytes (Fig. 5C and Video S). The micrograph displays the overlap of green and red fluorescence, which indicated the HepG2-mitoGFP received the mitochondrial form labeled BMSCs (Fig. 5D).

Flow cytometry corroborated mitochondrial metastasis. MitoTracker Red-labeled $\mathrm{mHCs}$ isolated from HFD mice were co-cultured with BMSCs-mito-GFP with different cell proportions $(11: 1 / 1: 3,1: 5,1: 9$, and 1:11) for 24 or $48 \mathrm{~h}$. Double-stained cells were differentiated using flow cytometry. In the same proportion of isolated mHCs, the number of double-stained cells

\footnotetext{
(See figure on next page.)

Fig. 5 Mitochondria transfer from BMSCs to steatotic cells. A The detection of GFP signaling in liver after BMSCs-mito-GFP for one week using an in vivo imaging system. All statistical data are represented as means $\pm s$. ${ }^{* *} P<0.001$. B The detection of mito-GFP signaling from BMSCs in liver. Blue, nucleus; Green, mito-GFP. Scale bar $=10 \mu \mathrm{m}$. C Representative micrographs of isolated mHCs from T2DM mice and BMSCs-mito-GFP after co-cultivation for 12 h. Green, BMSCs-mito-GFP; Red, MitoTracker Red. Scale bar = $20 \mu$ m. D Representative micrographs of labeled BMSCs and HepG2-mito-GFP after co-cultivation for 12 h. Green, HepG2-mito-GFP; Red, MitoTracker Red. Scale bar = 20 um. E Flow cytometry detects the double-stained cells. Labeled $\mathrm{mHCs}$ isolated form HFD mice were co-cultured with BMSCs-mito-GFP with different cell proportions (11:1/1:3/1:5/1:9/1:11) for $48 \mathrm{~h}$, after which these cells were screened using $2.5 \mathrm{\mu g} / \mathrm{mL}$ puromycin. Q2 represents the double-stained cells. $\mathbf{F}$ Schematic diagram of experimental design to verify mitochondrial transfer. HepG2 cells were planted at the bottom of a transwell dish with FFA medium for $36 \mathrm{~h}$. Then, the FFA medium was replaced with complete medium, after which BMSCs were inoculated at the upper chamber with $0.4 \mu \mathrm{m}$ or $0.22 \mu \mathrm{m}$ filter membrane for $24 \mathrm{~h}$ or $48 \mathrm{~h}$. G The mtDNA detection via gel electrophoresis at $24 \mathrm{~h}$ and $48 \mathrm{~h}$
} 


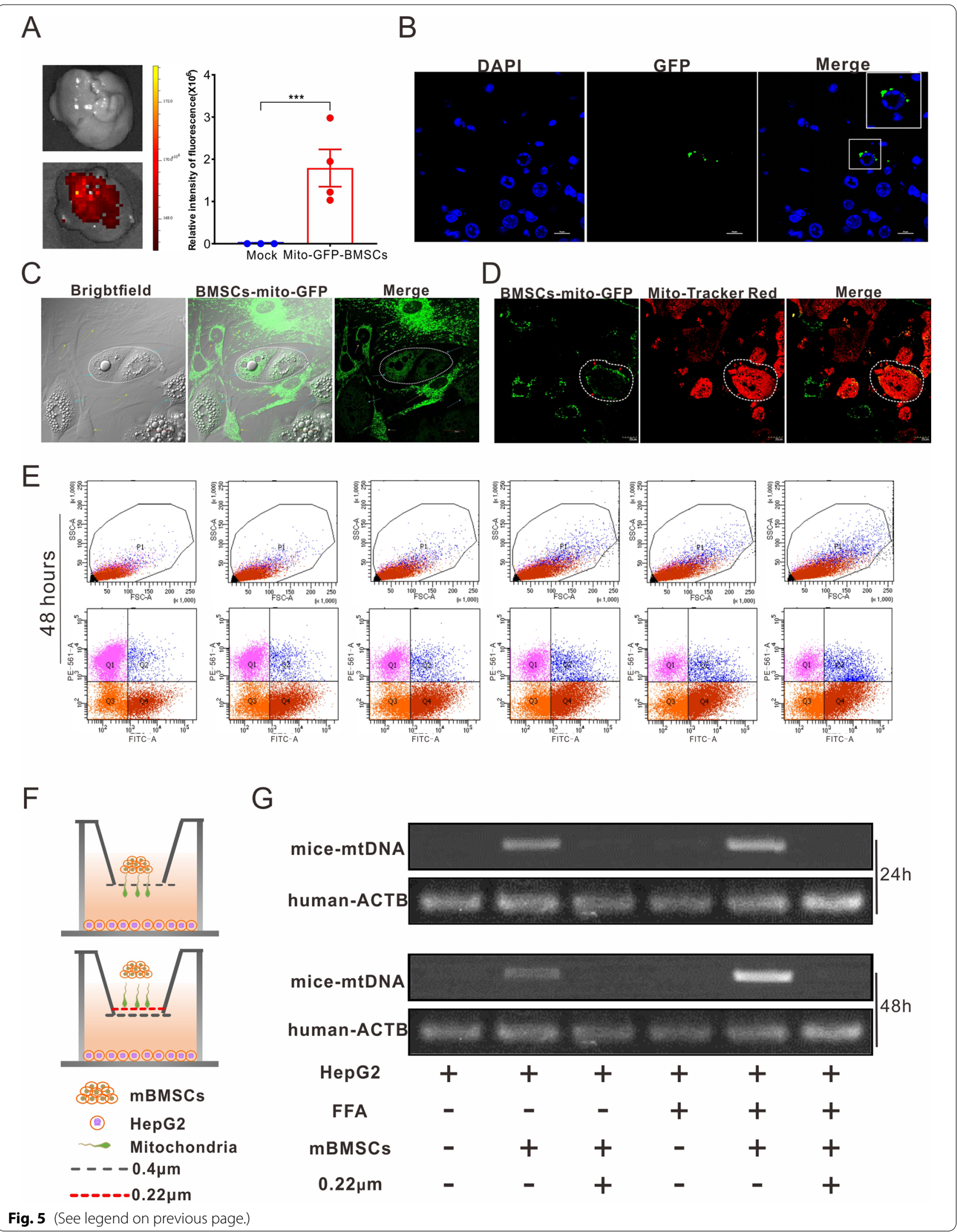


positively correlated with the seed number of BMSCs. Increased co-culture time also contributed more to the increase in the number of double-stained cells (Fig. 5E and Additional file 1: Fig. S6). Moreover, we investigated mitochondrial transfer in vitro. HepG2 cells and BMSCs were seeded at the bottom and top chambers of a transwell device, respectively, with $0.4 \mu \mathrm{m}$ or $0.22 \mu \mathrm{m}$ membrane for $24 \mathrm{~h}$ or $48 \mathrm{~h}$ culture (Fig. 5F). RNA from HepG2 cells in the lower layer was extracted for cDNA preparation. mtDNA was detected using PCR analysis, and the human-specific gene ACTB was used as the control. The electrophoresis bands indicated that mtDNA from BMSCs appeared in HepG2 cells regardless of FFA feed. However, this situation was blocked by a $0.22 \mu \mathrm{m}$ membrane pasted to the upper chamber (Fig. 5G). This comprehensively supports the mitochondrial transfer from BMSCs to HepG2 cells.

\section{Mitochondrial transfer dominates the rescue of steatotic cells not paracrine signaling}

Many studies have reported that BMSC paracrine signaling plays a crucial role in combating pathological stress [22]. To investigate the treatment effect of mitochondrial transfer to steatotic cells, we performed trials to verify the importance of mitochondrial transfer in alleviating steatosis. Oil Red $\mathrm{O}$ staining and cell ultrathin sections were used to detect steatosis and mitochondria. The results revealed that mito-block failed to rescue steatosis; however, there was still a slight improvement compared to the control (Fig. 6A). SEM micrographs showed that mito-block also could not correct the abnormal mitochondria, including morphology and number, in steatotic cells (Fig. 6B). Thereafter, the OCR analysis indicated that the mito-block was less effective than the unblocked condition. The monitoring of maximal and spare respiratory levels both showed a significant decrease in BMSC administration compared to those of the mito-block condition (Fig. 6C, D). Moreover, unit ATP production and MMP levels did not rebound when mitochondrial transfer from BMSCs was blocked. Under mito-block conditions, ROS levels did not decrease to normal levels (Fig. 6E). These results show that mitochondrial transfer from BMSCs dominates the rescue of steatotic cells, not paracrine signaling.

\section{Discussion}

NAFLD has become a global epidemic disease associated with multiple metabolic disorders, such as obesity and T2DM $[3,4]$. The coexistence of NAFLD and T2DM creates a worse metabolic profile, resulting in an increased risk of cardiovascular diseases, advanced fibrosis or cirrhosis, and even HCC [44, 45]. NAFLD and T2DM can be improved by dietary changes, increasing physical activity, and other treatment options such as metformin [46]. Moreover, there is currently no approved pharmacological agent specially developed for NAFLD. At this time, BMSCs have increased interest through the effect on chronic liver injury caused by decreasing apoptosis and immune imbalance [47, 48]. In a rodent model of fulminant hepatic failure and liver fibrosis, BMSC administration notably improved the pathological injury of the liver [49]. Additionally, BMSCs reversed HFD-induced NAFLD by suppressing CD4+ T lymphocytes in mice [50]. However, there are no reports on evaluating the treatment effect of BMSCs on NAFLD in T2DM. To date, only two studies have detailed the therapeutic effect of BMSCs on the HFD-induced rodent NAFLD model [50, 51]. However, neither has described the role of BMSCs in T2DM-associated NAFLD. This study established a T2DM model through 26-week HFD feeding, leading to severe liver steatosis and disordered glucose metabolism. Thereafter, the mice received two BMSC injections for the treatment evaluation. Particularly, mice were not withdrawn from HFD feeding after BMSC transplantation. Comprehensive analysis revealed that BMSC transplantation alleviated the collapsed liver function, hepatic steatosis, and lipid accumulation supported by reversing the evaluated AST and ALT to normal levels, lowering the AST/ALT ratio, and relieving histological lesions in the liver tissue. Moreover, BMSCs improved the disturbed glucose and lipid metabolism demonstrated by restoring GTT and ITT levels to normal levels and lowering the abnormal TG, TC, LDL, and HDL levels. It is worth mentioning that the GTT level had an exception after BMSC infusion for 4 weeks compared to the detection levels at 36th and 45th week. Although BMSC administration significantly reduced the body weight compared to that of diabetic obese mice, the mice were still significantly heavier than normal. The stubborn fat

\footnotetext{
(See figure on next page.)

Fig. 6 Mitochondrial transfer dominates the rescue of steatotic cells over paracrine signaling. Cells were processed as the description in Fig. 5F. A Representative micrographs of Oil Red O-stained cells and the quantification of stained area. B TEM imaging of differently treated cells, and the quantification of average mitochondrial number at $500 \mathrm{~nm}$. Twenty-five fields per group were taken into consideration. C OCR assay of differently treated cells. D Relative OCR comparison in terms of basal, maximal, and spare respiratory levels. E Detection of relative ATP, MMP, and ROS levels in differently treated cells. BMSCs-group and BMSCs-0.22 $\mu \mathrm{m}$-group indicate BMSCs were planted at the upper chamber with $0.4 \mu \mathrm{m}$ or $0.22 \mu \mathrm{m}$ filter membrane, respectively. HepG2-group means HepG2 cells were planted at the upper chamber with $0.4 \mu \mathrm{m}$ filter membrane. All trials above were performed with three independent replicates, and the statistical data are represented as means \pm s. ${ }^{*} P<0.05$; ${ }^{* *} P<0.01 ;{ }^{* * *} P<0.001$
} 


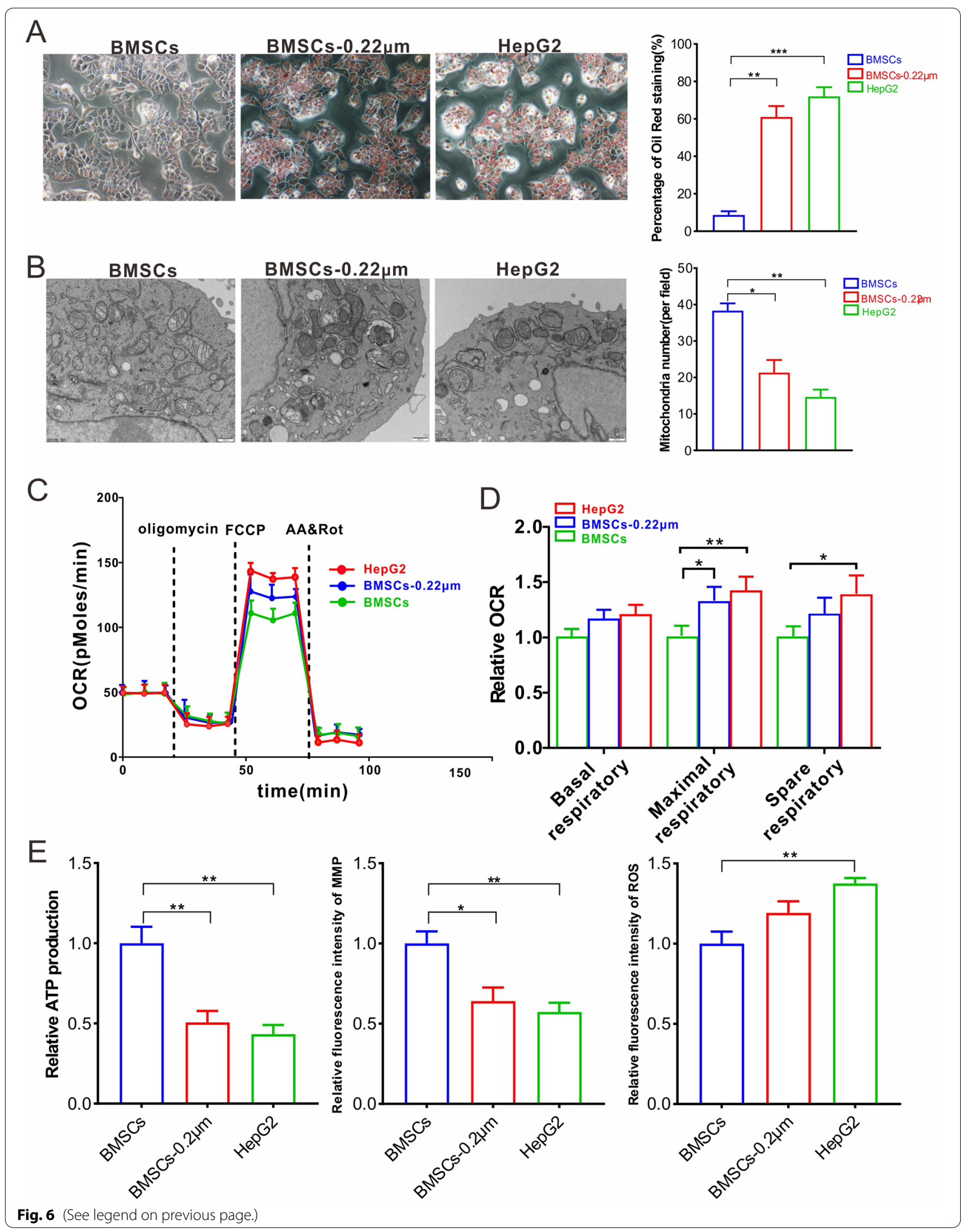


accumulation in the abdomen of the therapy group may be attributed to the above results. Therefore, it is necessary to further increase the therapeutic effect after increasing the total number of injections and the number of injected cells.

Mitochondria serve as cellular power plants that generate ATP by utilizing substrates derived from fat and glucose [11]. Hepatocytes have robust mitochondrial reserves. An increasing number of studies have confirmed that mitochondrial dysfunction is closely related to NAFLD pathogenesis, which raised the viewpoint that NAFLD is a mitochondrial disease $[16,52]$. In this study, electronic microscopy showed that mitochondria in NAFLD were large and swollen and scarce in number, and the cristae disappeared. The alteration of mitochondrial morphology resulted in inefficient oxygen use, decreased ATP production, total mtDNA, mRNA levels of MQC-related genes, and MMP, and increased ROS levels in hepatocytes. All these effects were effectively reversed by BMSC transplantation. Based on the evidence reported previously, our study confirms that mitochondrial dysfunction is a primary mechanism for NAFLD development. Mitochondrial dysfunction results in fat accumulation and leads to ROS generation, contributing to NAFLD progression. Mitochondrial correction may be an optimal treatment strategy for NAFLD.

The mitochondrial transfer enables the replacement of damaged mitochondria in diseased cells to reduce ROS production, introduce new exogenous bases for mtDNA repair, upregulate ATP yield, and slow down calcium influx $[23,28,53]$. Ismlam et al. first reported that BMSCs could supply robust mitochondria to alveolar epithelial cells in a rodent model of E. coli lipopolysaccharide-induced acute lung injury [54]. In our study, we observed that the delivery of mitochondria from BMSCs into steatotic cells increased OXPHOS activity and ATP levels, which in turn maintained cellular bioenergetics and recovered hepatocyte function. By contrast, blocking mitochondrial transfer deterred the protective effects of BMSCs. Classical mechanisms of paracrine release of cytokines and growth factors are related to rescuing damaged cells. However, mitochondria-free paracrine effect contributed less to rescue steatotic cells in vitro within $48 \mathrm{~h}$. Hence, we speculate that mitochondrial transfer from BMSCs, not paracrine signaling, dominates the rescue of damaged cells. Several studies have also stated that the horizontal transfer of mitochondria from one cell to another rescues the damaged cells with healthy ones, such as MSCs [54, 55]. Additionally, the natural intercellular mitochondrial transfer of MSCs enhances the immune response of macrophages. Rustom et al. first described the intercellular organelle transport between cells [56], from which multiple studies showed that MSCs are the best cells to transfer mitochondria $[28,54,57]$. Considering the reliable benefits of natural mitochondrial transfer, it is urgent to better understand its mechanism to facilitate the artificial replication of this process.

Our investigation is the first to report that BMSCs correct diabetes-associated NAFLD and emphasized that the nature of the cellular mitochondrial transfer is crucial for the above process to rescue steatotic cells. Nevertheless, there are still many issues that need to be resolved. Increasing reports support paracrine participants in immune regulation and tissue regeneration in NAFLD [58], and further investigation should focus on the crosstalk between BMSCs and other mitochondria-recipient cells such as macrophages and stellate cells. Additionally, the mitochondrial morphology and its plasticity allow it to be transported by subcellular transport mechanisms such as tunneling nanotubes and extracellular vesicles $[57,59]$. A better understanding of the process of mitochondrial transfer from BMSCs is beneficial for promoting the efficiency of mitochondrial transfer. The techniques currently in use today include con-incubation of isolated mitochondria and recipient cells and physical approaches to induce integration. Another priority is to determine the optimum quality of mitochondria for tissue repair by improving the current artificial transfer methods. Mitochondria are more than cell power plants. Therefore, we should continue to develop their application in medicine.

\section{Conclusion}

In summary, our study first revealed that BMSCs can alleviated the steatosis in diabetes-associated NAFLD mice. Moreover, mitochondrial transfer from BMSCs contributed greatly to combating steatosis via revising dysfunction mitochondrial, and has a promising therapeutic effect on NAFLD.

\section{Abbreviations}

BMSC: Bone marrow mesenchymal stem cell; NAFLD: Non-alcoholic fatty liver disease; T2DM: Type 2 diabetes mellitus; HFD: High-fat diet; MMP: Mito-

chondrial membrane potential; ROS: Reactive oxygen species; HCC: Hepatic carcinoma; MQC: Mitochondrial quality control; mtDNA: Mitochondrial DNA; WHO: World Health Organization; mHCs: Mouse hepatocytes; OCR: Oxygen consumption rate; MDA: Malondialdehyde; FFA: Free fatty acid; TEM: Transmission electron microscope; FCCP: $p$-Trifluoromethoxyphenylhydrazone.

\section{Supplementary Information}

The online version contains supplementary material available at https://doi. org/10.1186/s13287-021-02663-5.

Additional file 1: Fig. S1. Establishment of T2D-associated NAFLD mouse model. (A) The body weight monitoring of mice fed with HFD or ND from 6th week to 32nd week. (B) The detection of serum insulin at 32nd week. (C) The GTT and ITT assay at 32nd week. (D) The detection of serum ALT 
and AST at 32nd week. All statistical data are represented as means $\pm \mathrm{s}$. ${ }^{*} P<0.05 ;{ }^{* *} P<0.01 ;{ }^{* * *} P<0.001$. Fig. S2. The identification of BMSCs. (A) The representative micrographs of the 4th passage BMSCs (a1); Adipogenic differentiation of the 6 th passage BMSCs (Oli Red O stain of lipid droplets); Osteogenic differentiation of BMSCs (Alizarin Red stain for calcium). Scale bars $10 \mu \mathrm{m}$. (B) Representative flow cytometry analysis of cellsurface markers in the 6th passage BMSCs. All BMSCs expressed cell markers included CD73 and CD90.2, however negative for CD34 and CD45. Fig. S3. Representative images of HE stained BAT sections. ND, normal diet; HFD, high fatty diet; HFD-BMSC, high fatty diet mice with BMSC administration. Fig. S4. The calculations of mean OCR of the isolated mHCs at different stage corrected to basal OCR, maximal respiratory and spare respiratory capacity. The mHCs were isolated from ND, HFD-NS, and HFDBMSCs mice at 45th week. All statistical data are represented as means $\pm \mathrm{s}$. ${ }^{*} P<0.05 ;{ }^{*} P<0.01$. Fig. S5. The flow cytometry analysis of mitochondrial ROS of different cells at $24 \mathrm{~h}$ and $48 \mathrm{~h}$, respectively. HepG2-mito-GFP cells were cultured in FFA medium for $36 \mathrm{~h}$ and then co-cultured with BMSCs (FFA-BMSCs group) or not (FFA group) for another $24 \mathrm{~h}$ or $48 \mathrm{~h}$. All statistical data are represented as means $\pm s .{ }^{*} P<0.01$. Fig. S6. Flow cytometry detects the double-stained cells. Labeled $\mathrm{mHCs}$ isolated form HFD mice were co-cultured with BMSCs-mito-GFP with different cell proportions (11:1/1:3/1:5/1:9/1:11) for $24 \mathrm{~h}$, after which these cells were screened using $2.5 \mathrm{\mu g} / \mathrm{mL}$ puromycin. Q2 represents the double-stained cells. Table $\mathbf{S 1}$ Sequence information for the analysis of $\mathrm{mtDNA} / \mathrm{nDNA}$ ratio. Table $\mathbf{S 2}$. Sequence information of MQC-relevant genes.

\section{Acknowledgements}

The authors thank Xinlong Qiao from University of Chinese Academy of Sciences and Shuyan Qin from Nanyang Second General Hospital for their kindly help in crucial reading and suggestions.

\section{Authors' contributions}

$Y B, M Z, X G$, and GJ conceived and designed the experiments. YB, MZ, KZ, CS, $B F, Y W$, and $Z Y$ performed the experiments and contributed reagents/materials/analysis tools. YB, MZ, and GJ wrote the paper. All authors have read and approved the manuscript.

\section{Funding}

This work was supported by grants from the National Key Research and Development Project (2019YFA0110400 to GJ) and the National Foundation of Sciences and Technology (31971051, 31771562 to GJ).

\section{Availability of data and materials}

All datasets used and/or analyzed during the current study are available from the corresponding author on reasonable request.

\section{Declarations}

\section{Ethics approval and consent to participate}

All animal experiments were performed following the guidelines of laboratory animal care (NIH Publication No. 85-23, revised 1996) and with approval from the Institute of Biophysics Committee for Animal Care (Approval No. SYXK2019062).

\section{Consent for publication}

Not applicable.

\section{Competing interests}

The authors declare no potential conflict of interest.

\section{Author details}

${ }^{1}$ Institute of Biophysics, Chinese Academy of Sciences, Beijing 100101, China. ${ }^{2}$ Puyang Oilfield General Hospital, Affiliated to Xinxiang Medical College, Puyang city 457000 , Henan Province, China. ${ }^{3}$ University of Chinese Academy of Sciences, Beijing 100049, China.

Received: 7 September 2021 Accepted: 11 November 2021

Published online: 11 December 2021

\section{References}

1. Diehl AM, Day C. Cause, pathogenesis, and treatment of nonalcoholic steatohepatitis. N Engl J Med. 2017;377(21):2063-72. https://doi.org/10. 1056/NEJMra1503519.

2. Pafili K, Roden M. Nonalcoholic fatty liver disease (NAFLD) from pathogenesis to treatment concepts in humans. Mol Metab. 2021;50:101122. https://doi.org/10.1016/j.molmet.2020.101122.

3. Kisseleva T, Brenner DA. The crosstalk between hepatocytes, hepatic macrophages, and hepatic stellate cells facilitates alcoholic liver disease. Cell Metab. 2019;30(5):850-2. https://doi.org/10.1016/j.cmet.2019.10.010.

4. Meex RCR, Watt MJ. Hepatokines: linking nonalcoholic fatty liver disease and insulin resistance. Nat Rev Endocrinol. 2017;13(9):509-20. https://doi. org/10.1038/nrendo.2017.56.

5. Kumar S, Duan Q, Wu R, Harris EN, Su Q. Pathophysiological communication between hepatocytes and non-parenchymal cells in liver injury from NAFLD to liver fibrosis. Adv Drug Deliv Rev. 2021. https://doi.org/10. 1016/j.addr.2021.113869.

6. Targher G, Corey KE, Byrne CD, Roden M. The complex link between NAFLD and type 2 diabetes mellitus-mechanisms and treatments. Nat Rev Gastroenterol Hepatol. 2021. https://doi.org/10.1038/ s41575-021-00448-y.

7. Younossi ZM, Golabi P, de Avila L, Paik JM, Srishord M, Fukui N, Qiu Y, Burns L, Afendy A, Nader F. The global epidemiology of NAFLD and NASH in patients with type 2 diabetes: a systematic review and meta-analysis. J Hepatol. 2019;71(4):793-801. https://doi.org/10.1016/j.jhep.2019.06.021.

8. Ipsen DH, Lykkesfeldt J, Tveden-Nyborg P. Molecular mechanisms of hepatic lipid accumulation in non-alcoholic fatty liver disease. Cell Mol Life Sci. 2018;75(18):3313-27. https://doi.org/10.1007/s00018-018-2860-6.

9. Parker R, Aithal GP, Becker U, Gleeson D, Masson S, Wyatt JI, Rowe IA. Natural history of histologically proven alcohol-related liver disease: a systematic review. J Hepatol. 2019;71(3):586-93. https://doi.org/10.1016/j. jhep.2019.05.020

10. Tilg H, Moschen AR, Roden M. NAFLD and diabetes mellitus. Nat Rev Gastroenterol Hepatol. 2017;14(1):32-42. https://doi.org/10.1038/nrgas tro.2016.147.

11. Spinelli JB, Haigis MC. The multifaceted contributions of mitochondria to cellular metabolism. Nat Cell Biol. 2018;20(7):745-54. https://doi.org/10. 1038/s41556-018-0124-1.

12. Krabbendam IE, Honrath B, Culmsee C, Dolga AM. Mitochondrial Ca(2+)activated $\mathrm{K}(+)$ channels and their role in cell life and death pathways. Cell Calcium. 2018;69:101-11. https://doi.org/10.1016/j.ceca.2017.07.005.

13. Nolfi-Donegan D, Braganza A, Shiva S. Mitochondrial electron transport chain: oxidative phosphorylation, oxidant production, and methods of measurement. Redox Biol. 2020;37:101674. https://doi.org/10.1016/j. redox.2020.101674

14. Kupriyanova Y, Zaharia OP, Bobrov P, Karusheva Y, Burkart V, Szendroedi J, Hwang $\mathrm{JH}$, Roden M. Early changes in hepatic energy metabolism and lipid content in recent-onset type 1 and 2 diabetes mellitus. J Hepatol. 2021;74(5):1028-37. https://doi.org/10.1016/j.jhep.2020.11.030.

15. Ni H-M, Williams JA, Ding W-XJRb,. Mitochondrial dynamics and mitochondrial quality control. Redox Biol. 2015;4:6-13.

16. Li R, Toan S, Zhou H. Role of mitochondrial quality control in the pathogenesis of nonalcoholic fatty liver disease. Aging. 2020;12(7):6467-85. https://doi.org/10.18632/aging.102972.

17. Rong $X$, Liu J, Yao X, Jiang T, Wang Y, Xie F. Human bone marrow mesenchymal stem cells-derived exosomes alleviate liver fibrosis through the Wnt/ß-catenin pathway. Stem Cell Res Ther. 2019;10(1):98. https://doi. org/10.1186/s13287-019-1204-2.

18. Rong X, Yang Y, Zhang G, Zhang H, Li C, Wang Y. Antler stem cells as a novel stem cell source for reducing liver fibrosis. Cell Tissue Res. 2020;379(1):195-206. https://doi.org/10.1007/s00441-019-03081-z.

19. Yao X, Wang J, Zhu J, Rong $X$. The anti-fibrotic effect of human fetal skin-derived stem cell secretome on the liver fibrosis. Stem Cell Res Ther. 2020;11(1):379. https://doi.org/10.1186/s13287-020-01891-5.

20. Gao J, Yuan J, Liu Q, Wang Y, Wang H, Chen Y, Ding W, Ji G, Lu Z. Adiposederived stem cells therapy effectively attenuates PM(2.5)-induced lung injury. Stem Cell Res Ther. 2021;12(1):355. https://doi.org/10.1186/ s13287-021-02441-3.

21. Porada CD, Almeida-Porada G. Mesenchymal stem cells as therapeutics and vehicles for gene and drug delivery. Adv Drug Deliv Rev. 2010;62(12):1156-66. https://doi.org/10.1016/j.addr.2010.08.010. 
22. Pittenger MF, Discher DE, Péault BM, Phinney DG, Hare JM, Caplan Al. Mesenchymal stem cell perspective: cell biology to clinical progress. NPJ Regen Med. 2019;4:22. https://doi.org/10.1038/s41536-019-0083-6.

23. Court AC, Le-Gatt A, Luz-Crawford P, Parra E, Aliaga-Tobar V, Bátiz LF, Contreras RA, Ortúzar MI, Kurte M, Elizondo-Vega R, Maracaja-Coutinho V, Pino-Lagos K, Figueroa FE, Khoury M. Mitochondrial transfer from MSCs to T cells induces Treg differentiation and restricts inflammatory response. EMBO Rep. 2020;21 (2):e48052. https://doi.org/10.15252/embr.201948052.

24. Jiang D, Gao F, Zhang Y, Wong DS, Li Q, Tse HF, Xu G, Yu Z, Lian Q. Mitochondrial transfer of mesenchymal stem cells effectively protects corneal epithelial cells from mitochondrial damage. Cell Death Dis. 2016;7(11):e2467. https://doi.org/10.1038/cddis.2016.358.

25. Li C, Cheung MKH, Han S, Zhang Z, Chen L, Chen J, Zeng H, Qiu J. Mesenchymal stem cells and their mitochondrial transfer: a double-edged sword. 2019. Biosci Rep. https://doi.org/10.1042/bsr20182417.

26. Mohammadalipour A, Dumbali SP, Wenzel PL. Mitochondrial transfer and regulators of mesenchymal stromal cell function and therapeutic efficacy. Front Cell Dev Biol. 2020;8:603292. https://doi.org/10.3389/fcell. 2020.603292.

27. Paliwal S, Chaudhuri R, Agrawal A, Mohanty S. Regenerative abilities of mesenchymal stem cells through mitochondrial transfer. J Biomed Sci. 2018:25(1):31. https://doi.org/10.1186/s12929-018-0429-1.

28. Spees JL, Olson SD, Whitney MJ, Prockop DJ. Mitochondrial transfer between cells can rescue aerobic respiration. Proc Natl Acad Sci U S A. 2006;103(5):1283-8. https://doi.org/10.1073/pnas.0510511103.

29. Liu D, Gao Y, Liu J, Huang Y, Yin J, Feng Y, Shi L, Meloni BP, Zhang C, Zheng M, Gao J. Intercellular mitochondrial transfer as a means of tissue revitalization. Signal Transduct Target Ther. 2021;6(1):65. https://doi.org/10.1038/ s41392-020-00440-z.

30. Swearengen JR. Common challenges in safety: a review and analysis of AAALAC findings. ILAR J. 2018;59(2):127-33. https://doi.org/10.1093/ilar/ ily011.

31. Graham L, Orenstein JM. Processing tissue and cells for transmission electron microscopy in diagnostic pathology and research. Nat Protoc. 2007;2(10):2439-50. https://doi.org/10.1038/nprot.2007.304.

32. Baribault $\mathrm{H}$. Mouse models of type 2 diabetes mellitus in drug discovery. Methods Mol Biol (Clifton, NJ). 2016;1438:153-75. https://doi.org/10. 1007/978-1-4939-3661-8_10.

33. Chen D, Li X, Zhang L, Zhu M, Gao L. A high-fat diet impairs mitochondrial biogenesis, mitochondrial dynamics, and the respiratory chain complex in rat myocardial tissues. J Cell Biochem. 2018;119(11):9602. https://doi. org/10.1002/jcb.27068.

34. Dorn GW 2nd, Vega RB, Kelly DP. Mitochondrial biogenesis and dynamics in the developing and diseased heart. Genes Dev. 2015;29(19):1981-91. https://doi.org/10.1101/gad.269894.115.

35. Ayala A, Muñoz MF, Argüelles S. Lipid peroxidation: production, metabolism, and signaling mechanisms of malondialdehyde and 4-hydroxy2-nonenal. Oxid Med Cell Longev. 2014. https://doi.org/10.1155/2014/ 360438.

36. Yang XX, Wang $X$, Shi TT, Dong JC, Li FJ, Zeng LX, Yang M, Gu W, Li JP, Yu J. Mitochondrial dysfunction in high-fat diet-induced nonalcoholic fatty liver disease: the alleviating effect and its mechanism of Polygonatum kingianum. Biomed Pharmacother. 2019;117:109083. https://doi.org/10. 1016/j.biopha.2019.109083.

37. Betz C, Stracka D, Prescianotto-Baschong C, Frieden M, Demaurex N, Hall MN. Feature article: mTOR complex 2-Akt signaling at mitochondria-associated endoplasmic reticulum membranes (MAM) regulates mitochondrial physiology. Proc Natl Acad Sci U S A. 2013;1 10(31):12526-34. https:// doi.org/10.1073/pnas.1302455110.

38. Camara AKS, Zhou Y, Wen PC, Tajkhorshid E, Kwok WM. Mitochondrial VDAC1: a key gatekeeper as potential therapeutic target. Front Physiol. 2017:8:460. https://doi.org/10.3389/fphys.2017.00460.

39. Bansal S, Biswas G, Avadhani NG. Mitochondria-targeted heme oxygenase-1 induces oxidative stress and mitochondrial dysfunction in macrophages, kidney fibroblasts and in chronic alcohol hepatotoxicity. Redox Biol. 2014;2:273-83. https://doi.org/10.1016/j.redox.2013.07.004.
40. Gaspers LD, Pierobon N, Thomas AP. Intercellular calcium waves integrate hormonal control of glucose output in the intact liver. J Physiol. 2019;597(11):2867-85. https://doi.org/10.1113/jp277650.

41. Ozcan L, Wong CC, Li G, XU T, Pajvani U, Park SK, Wronska A, Chen BX, Marks AR, Fukamizu A, Backs J, Singer HA, Yates JR 3rd, Accili D, Tabas I. Calcium signaling through CaMKII regulates hepatic glucose production in fasting and obesity. Cell Metab. 2012;15(5):739-51. https://doi.org/10. 1016/j.cmet.2012.03.002.

42. Wang $X$, Cai $B$, Yang $X$, Sonubi OO, Zheng Z, Ramakrishnan $R$, Shi H, Valenti L, Pajvani UB, Sandhu J, Infante RE, Radhakrishnan A, Covey DF, Guan KL, Buck J, Levin LR, Tontonoz P, Schwabe RF, Tabas I. Cholesterol stabilizes TAZ in hepatocytes to promote experimental non-alcoholic steatohepatitis. Cell Metab. 2020;31(5):969-986.e967. https://doi.org/10.1016/j.cmet. 2020.03.010.

43. Zhang L, Zhang Y, Jiang Y, Dou X, Li S, Chai H, Qian Q, Wang M. Upregulated SOCC and IP3R calcium channels and subsequent elevated cytoplasmic calcium signaling promote nonalcoholic fatty liver disease by inhibiting autophagy. Mol Cell Biochem. 2021;476(8):3163-75. https:// doi.org/10.1007/s11010-021-04150-0.

44. Kasper P, Martin A, Lang S, Kütting F, Goeser T, Demir M, Steffen HM. NAFLD and cardiovascular diseases: a clinical review. Clin Res Cardiol Off J Ger Card Soc. 2021;110(7):921-37. https://doi.org/10.1007/ s00392-020-01709-7.

45. Vieira Barbosa J, Lai M. Nonalcoholic fatty liver disease screening in type 2 diabetes mellitus patients in the primary care setting. Hepatol Commun. 2021;5(2):158-67. https://doi.org/10.1002/hep4.1618.

46. Komorizono Y, Hosoyamada K, Imamura N, Kajiya S, Hashiguchi Y, Ueyama N, Shinmaki H, Koriyama N, Tsukasa M, Kamada T. Metformin dose increase versus added linagliptin in non-alcoholic fatty liver disease and type 2 diabetes: an analysis of the J-LINK study. Diabetes Obes Metab. 2021;23(3):832-7. https://doi.org/10.1111/dom.14263.

47. Fathi-Kazerooni M, Tavoosidana G, Taghizadeh-Jahed M, Khanjani S, Golshahi H, Gargett CE, Edalatkhah H, Kazemnejad S. Comparative restoration of acute liver failure by menstrual blood stem cells compared with bone marrow stem cells in mice model. Cytotherapy. 2017;19(12):147490. https://doi.org/10.1016/j.jcyt.2017.08.022.

48. Lyra AC, Soares MB, dos Santos RR, Lyra LG. Bone marrow stem cells and liver disease. Gut. 2007;56(11):1640 (author reply 1640-1641).

49. Huang $B$, Cheng $X$, Wang $H$, Huang $W$, la Ga HuZ, Wang D, Zhang K, Zhang H, Xue Z, Da Y, Zhang N, Hu Y, Yao Z, Qiao L, Gao F, Zhang R. Mesenchymal stem cells and their secreted molecules predominantly ameliorate fulminant hepatic failure and chronic liver fibrosis in mice respectively. J Transl Med. 2016;14:45. https://doi.org/10.1186/ s12967-016-0792-1.

50. Wang H, Zhang H, Huang B, Miao G, Yan X, Gao G, Luo Y, Chen H, Chen $W$, Yang L. Mesenchymal stem cells reverse high-fat diet-induced nonalcoholic fatty liver disease through suppression of CD4+ T lymphocytes in mice. Mol Med Rep. 2018;17(3):3769-74. https://doi.org/10.3892/mmr. 2017.8326

51. Li L, Zeng X, Liu Z, Chen X, Li L, Luo R, Liu X, Zhang J, Liu J, Lu Y, Cheng J, Chen Y. Mesenchymal stromal cells protect hepatocytes from lipotoxicity through alleviation of endoplasmic reticulum stress by restoring SERCA activity. J Cell Mol Med. 2021;25(6):2976-93. https://doi.org/10.1111/ jcmm.16338.

52. Koch L. Metabolism: mitochondrial pathways in NAFLD. Nat Rev Endocrinol. 2012;8(3):129. https://doi.org/10.1038/nrendo.2011.240.

53. Torralba D, Baixauli F, Sánchez-Madrid F. Mitochondria know no boundaries: mechanisms and functions of intercellular mitochondrial transfer. Front Cell Dev Biol. 2016;4:107. https://doi.org/10.3389/fcell.2016.00107.

54. Islam MN, Das SR, Emin MT, Wei M, Sun L, Westphalen K, Rowlands DJ, Quadri SK, Bhattacharya S, Bhattacharya J. Mitochondrial transfer from bone-marrow-derived stromal cells to pulmonary alveoli protects against acute lung injury. Nat Med. 2012;18(5):759-65. https://doi.org/10.1038/ nm.2736.

55. Ahmad T, Mukherjee S, Pattnaik B, Kumar M, Singh S, Kumar M, Rehman R, Tiwari BK, Jha KA, Barhanpurkar AP, Wani MR, Roy SS, Mabalirajan U, Ghosh B, Agrawal A. Miro1 regulates intercellular mitochondrial 
transport and enhances mesenchymal stem cell rescue efficacy. EMBO J. 2014;33(9):994-1010. https://doi.org/10.1002/embj.201386030.

56. Rustom A, Saffrich R, Markovic I, Walther P, Gerdes HH. Nanotubular highways for intercellular organelle transport. Science (New York, NY). 2004;303(5660):1007-10. https://doi.org/10.1126/science.1093133.

57. Jackson MV, Morrison TJ, Doherty DF, McAuley DF, Matthay MA, Kissenpfennig A, O'Kane CM, Krasnodembskaya AD. Mitochondrial transfer via tunneling nanotubes is an important mechanism by which mesenchymal stem cells enhance macrophage phagocytosis in the in vitro and in vivo models of ARDS. Stem Cells. 2016;34(8):2210-23. https://doi.org/ 10.1002/stem.2372.

58. Loomba R, Friedman SL, Shulman Gl. Mechanisms and disease consequences of nonalcoholic fatty liver disease. Cell. 2021;184(10):2537-64. https://doi.org/10.1016/j.cell.2021.04.015.
59. Raposo G, Stoorvogel W. Extracellular vesicles: exosomes, microvesicles, and friends. J Cell Biol. 2013;200(4):373-83. https://doi.org/10.1083/jcb. 201211138.

60. Quiros PM, Goyal A, Jha P, Auwerx J. Analysis of mtDNA/nDNA ratio in mice. Curr Protoc Mouse Biol. 2017;7(1):47-54. https://doi.org/10.1002/ cpmo.21

\section{Publisher's Note}

Springer Nature remains neutral with regard to jurisdictional claims in published maps and institutional affiliations.
Ready to submit your research? Choose BMC and benefit from:

- fast, convenient online submission

- thorough peer review by experienced researchers in your field

- rapid publication on acceptance

- support for research data, including large and complex data types

- gold Open Access which fosters wider collaboration and increased citations

- maximum visibility for your research: over $100 \mathrm{M}$ website views per year

At BMC, research is always in progress.

Learn more biomedcentral.com/submissions 